\title{
Utilizing Health Belief Model to Enhance the Preventive Health Behavior about Osteoporosis among Young-Adult Females
}

\author{
Suzan El-Said Mansour ${ }^{1}$, Hanan El-Sayed Mohamed El-Sayed ${ }^{1}$, \\ Adel Al-Wehedy Ibrahim ${ }^{2}$ \\ ${ }^{1}$ Woman's Health \& Midwifery Nursing Department, Faculty of Nursing-Mansoura University, Egypt. \\ ${ }^{2}$ Public Health \& Community Medicine Department, Faculty of Medicine-Mansoura University, Egypt.
}

\begin{abstract}
This study aimed to evaluate utilization health belief model to enhance the preventive health behavior about osteoporosis among young-adult females.

Design: A quasi-experimental Pre\& Post design.

Sample type: Purposive sampling was applied, consisted of 60 young-adult females.

Setting: The study was carried out at gynecology clinic in Mansoura University Hospital, Egypt.

Tools: Self-administered Questionnaire, Osteoporosis Knowledge Test (OKT), Osteoporosis Health Belief Scale (OHBS) and Osteoporosis Self-Efficacy Scale (OSES).

Results: The total knowledge score of the studied sample about osteoporosis were improved significantly from (9.47 \pm 3.14$)$ pre-intervention to $(15.22 \pm 2.56)$ post-intervention with highly significant differences $(P=0.000)$. The average scores of susceptibility to osteoporosis, seriousness, benefits of exercise, benefits of Calcium (Ca) intake and health motivation were significantly increased post-intervention compared to the scores before $(p<0.05)$. Also, low level of perceived barriers of exercise and barriers to Ca intake were improved postintervention and was significantly only for barriers of Ca intake. Moreover, there was a significant improvement in osteoporosis self-efficacy scale whereas the total average score was $23.55 \pm 8.50$ preintervention compared to $41.62 \pm 7.97$ post-intervention with highly statistical significant difference $(P=0.000)$.

Conclusion: The study findings concluded that utilization of health belief model had positive effect for increasing knowledge; enhance health belief, and self-efficacy for prevention of osteoporosis among the youngadult females.

Recommendations: Applying health belief model based education on wide range of female's age group on different diseases and further research to clarify the behavioral and social barriers in calcium intake in different cultural contexts.

Keyword: Health Belief Model (HBM), Preventive Health Behavior, Osteoporosis, Young-Adult Females
\end{abstract}

\section{Introduction}

Osteoporosis (OP) is one of the most common bone metabolic disorders which have been associated with significant disability and mortality (Darba et al., 2015). It is a progressive chronic skeletal disease associated with low bone mass and micro-architectural impairment of bone tissue, leading to bone fragility and increased risk of fractures (Puttapitakpong et al., 2014). Large number of females spend one third of their postmenopausal period usually associated with an estrogen hormone shortage (Kanis et al., 2013). It is rated that two hundred million women worldwide affected by it and leads to approximately 8.9 million fractures every year (Watts et al., 2010).

Indeed, The National Osteoporosis Foundation (NOF) in 2014, reported that a sum of 54 million adults aged 50 and older in USA are influenced by OP and low bone mass (Wright et al., 2014). In Europe, in 2010 approximately 22 million women and 5.5 million men aged between 50 and 84 years are estimated to have OP (Hernlund et al., 2013). Furthermore, based on different studies implemented in Egypt that $28.4 \%$ of postmenopausal females have OP and 53.9\% have osteopenia (Taha, 2011).

Particularly, there are several controllable and uncontrollable risk factors are associated with osteoporosis. Low activity level, smoking, alcohol abuse, numerous years of sedentary lifestyle and insufficient diet including eating disorder, low calcium \& vitamin D intake, and excessive consumption of soft drinks are the most common controllable risk factors. Moreover, overuse of caffeine more than three cups daily consistently may increase excretion of calcium in the urine and it affects the bone wellbeing. While the uncontrollable factors comprise sex, family history, ethnicity and race, progressing age, status and body outline measures of post-menopausal women (National osteoporosis foundation, 2011).

Changing the behavior depends on individual's recognition and condition, Motivation in osteoporosis prevention is higher among menopausal women than pre-menopausal women because at that time they start to lose the bone mass (Ailinger et al., 2005). Osteoporosis is not frequently appearing till the bone has fractured, so most of females are unaware that they are at threat of osteoporosis. Lifestyle behaviors establish during 
young adulthood, afterwards long-term behavior change is difficult. Nevertheless, adequate dietary regiment and healthy lifestyle can assist in osteoporosis prevention from young age. So that, it is essential to store the bone mass while the menstrual periods continue through developing healthy life style behavior during adolescence and continue into adulthood because after this life stage, it is difficult to change the individual long-term lifestyle practices and behaviors ( Chan et al., 2005).

However, Osteoporosis is not treatable, but rather it can be prevented by increasing the physical activity level at all ages with sufficient intake of calcium, vitamin D in diet and prevention of fall. Discontinuation of smoking and alcohol consumption can play a role. Also, weight-bearing activities at least thirty minutes daily such as (jogging, going up and down stairs, aerobics, isometrics and swimming) can be important preventive measures against osteoporosis (National Osteoporosis Foundation, 2010).

Establishment of healthy lifestyle behaviors must be started from early especially the young adult age because most of them become self-centered and are not concerned in healthy life and it is not easy to change their behavior and lifestyle (Franzén, 2011). When the females have poor physical activity in youth, they will not be able to change in their adulthood. Most of females avoid eating enough balanced meats to keep themselves slim. Consequently, anorexia and low body weight associated with eating disorders can lead to less estrogen and missed menstrual periods (Papadopoulos, 2007). Additionally, many researchers identified that most of females are unawareness of osteoporosis and it's the risk factors (Gurney \& Simmonds, 2007).

Health Belief Model (HBM) is one of the theoretical models that used widely to increase the understanding of healthy behavior (Moodi \& Mood, 2011). Programs based on HBM are effective and inexpensive method for enhancing the knowledge and practices that required for establishing behavioral changes such as increasing calcium intake and physical activities for prevention of osteoporosis. It is based on the idea that individuals are willing to maintain wellbeing through following health-related action to avoid an undesirable health condition. This model emphasize that to design and prepare a successful educational intervention, the females have to understand the perceived susceptibility and seriousness (to osteoporosis); severity of the disease and its consequences; perceived benefits to reduce the risk by performing specific actions; perceived barriers (e.g., advised action expenses) and action cues (approaches for initiating the "willingness" to attempt the health activities and actions) are required (Vehei et al., 2007).

Enhancing the bone strength through health education can be effective in osteoporosis prevention especially among young females (Asakawa et al., 2011). Nurses are in effective, powerful and significant position to help the females from conception to older life to change their attitude regarding osteoporosis prevention and fracture risk (Gamal \& Rashed, 2015). Similarly they have a professional role and accountability regarding health promotion and disease prevention by advocating the females to maintain bone health and planning osteoporosis prevention programmers for young-adult age to decrease the risk of osteoporosis and thus, prevent or delay disease development (Royal College of Nursing, 2012).

Consequently, using health believe model as method for osteoporosis prevention through two measures, one is based on increasing the knowledge about osteoporosis and the other is related to preventive behavior and self-efficacy measures that reinforce attitude and behavioral change (Franzén, 2011).

\section{Significance of the Study:}

Currently, osteoporosis is one of the topmost five disorders leading to disability and prolonged hospital stay for post-menopausal females. Accordingly, osteoporosis is second only to cardiovascular disease as a global health care problem (WHO, 2012).

Since the peak bone mass is frequently reached by young-adult age and the bone density decreases with age. So that, achievements of peak bone mass and the consequent bone retention through middle age are important determinants for decreasing the risk of osteoporosis (Sasson \& Carpenter, 2013). Emphasizing osteoporosis prevention programs that comprise health education and health promotion through the aim of improving bone mass growth, to prevent loss of bone later in life (Babatundeet al., 2012). Taking the recommended doses of vitamin D \& calcium and maintain the physical activity in young adulthood are considered essential factors to ensure peak bone mass development and prevention of osteoporosis (Sunyecz, 2008).

Owing to the fact that osteoporosis is a silent and preventable in nature, therefore its prevention enhances awareness of risk factors and preventive behaviors are important for young adult females because it helps later in life (Franzén, 2011). So this study was conducted.

Aim of the Study:

This study aimed to utilize health belief model to enhance the preventive health behavior about osteoporosis among young-adult females. 
Research Hypothesis:

Health Belief Model (HBM) was expected to be effective method for enhancing the preventive health behaviors about osteoporosis evidenced by:

H1: Significant improvement in the female's knowledge level.

$\mathrm{H} 2$ : Significant change in the female's health beliefs about osteoporosis.

H3: Significant increase in the female's self-efficacy regarding osteoporosis.

Operational Definitions:

Health Belief Model: This model is used to enhance the preventive health behavior through its four factors. Also, it has been developed to contain cues to action, motivating elements and self-efficacy.

Preventive Health Behavior: Any action undertaken by an individual who believes herself/himself healthy for the purpose of disease preventing disease. It can be fostered by increasing individuals' knowledge and perceived self-efficacy as well decreasing perceived barriers.

Self-Efficacy: It's the belief in the individual's abilities to establish and organize the action essential to achieve targeted behavior.

\section{Study Design}

\section{Subjects and Method}

Quazi- experimental (pre\& post) research design was used.

Study Setting

The study was carried out at gynecology clinic in Mansoura University hospital, Egypt.

Study Subjects

Sixty young-adult females were chosen by purposive sampling according to inclusion \& exclusion criteria:

\section{Inclusion Criteria:}

- Women age ranged from 20-35 years.

- At least read and write.

- Willing to participate in the study.

\section{Exclusion Criteria:}

Females who loss menstrual period for 12 months or more, previous operation of oophorectomy, have a previous history of osteoporosis or genetic early osteoporosis, they previously participated in an osteoporosis preventive educational session, taking hormonal contraceptive methods, they had a chronic disease (e.g. cardiac disease, diabetes mellitus or renal failure).

\section{Sample Size:}

Using Dss-research.com software program, with $68.0 \%$ of women agree that duration of exercise must be 20 -30 min before education and became $88.0 \%$ after education (Malak \& Toama, 2015), with $5.0 \% \infty$ error ( $95.0 \%$ significance) and $20.0 \% \beta$ error ( 80.0 power of the study); the calculated sample size is 52 subject. The study conducted on sixty females to increase the quality of collected data.

\section{Data Collection Tools:}

Data were collected through:

Tool I: Self-administered Questionnaire: Covers the data related to general characteristics (age, educational, occupation, telephone number, marital status, breast feeding and smoking).

Tool II: Osteoporosis Knowledge Test (OKT): It was adopted from Kim et al, (1991a). Consisted of 24 items that measure female's knowledge toward osteoporosis; OKT was translated and used by the researchers. It has the knowledge about osteoporosis, exercises, food sources of calcium, recommended intake and supplementation of calcium \& calcium absorption. Answers were coded by assigning "1" for correct answer and " 0 " for incorrect answer. Total maximum score was 24 (Up to $<8$ was considered poor, from 8-16 considered fair and from 16-24 considered high.

Tool III: Osteoporosis Health Belief Scale (OHBS): It was adopted from Kim et al., (1991b) consisted of forty two items instrument including seven domains forming the health beliefs. The subscales are related to 
susceptibility, seriousness, benefits to exercise, benefits to calcium intake, barriers to exercise, barriers to calcium intake, and health motivation. Each domain has six specific subscales rated by using five point likert scales by each participant with $1=$ strongly disagree, $2=$ disagree, $3=$ neutral, $4=$ agree, and $5=$ strongly agree. Agree or strongly agree are correct responses. Scores had a possible range of 42 to 210 for the total health belief score and a possible range of 6 to 30 for each subscale score. Each scale consists from 6 questions, possible score for each subscale ranged between "6-30" with a low score indicating low perception and high score indicating high perception. Scale interpretation the above 6 subscale from (6-18 low perceived, \& high perceived 19-30) in relation to perceived health motivation subscale negative view of health 6-18 positive view of health from 19-30).

Tool IV: Osteoporosis Self-Efficacy Scale (OSES): The OSES was adopted from Horan et al., (1998) utilized a 12-item consisting of two subscales, an osteoporosis self-efficacy exercise scale and an osteoporosis selfefficacy calcium scale. The self-efficacy for exercise was evaluated using 6 items. Each participant responses on five likert scale of 1-5 ( $1=$ strongly disagree, $2=$ disagree, $3=$ neutral, $4=$ agree, and $5=$ strongly agree). The exercise and calcium score was calculated by averaging the response to each 6 related items and multiplying by 5(range: 0-30) to be grouped in to the following categories: low (6-18) and high (19-30).

\section{Validity of the Tools:}

Tools were reviewed by three jury experts and specialized university professors in maternity nursing field tested the content validity; According to their comments, modifications were considered.

Reliability:

According to Chen et al., (2005) reliability of tools were calculated with a Cronbach's alpha score to be: Tool II Cronbach's alpha coefficients for the three scales ranged from 0.83 to 0.87 , Tool III: Cronbach's alpha coefficients ranged from 0.68 to 0.85 and Tool IV: Cronbach's alpha coefficients ranged from 0.90 to 0.94 , hence the tools were found to be highly reliable.

\section{Ethical Considerations}

The researchers have obtained a written consent from the females included in the study. Females were reassured about information confidentiality. They were informed about their rights to refuse participation or withdraw at any time. The study maneuvers couldn't entail any cultural, religious and ethical harm to participants.

\section{Pilot Study}

A pilot study was conducted on six women in order to test the applicability and relevance of the study tools and test clarity of the designed questionnaire as well as to estimate the time needed to answer them and then the necessary modifications were done, these women were excluded from the study sample.

\section{Method:}

1. Formal permission was obtained from the head of the department at nursing faculty.

2. Official letter was sent to the manager of gynecology clinic at Mansoura University hospital.

3. Data collected from September to December 2016 on 60 young-adult females.

4. Prior to data collection the researchers introduced themselves and explained the purpose of the study.

5. Tools were distributed and explained to women to answer the study tools (pre- test format).

6. After completing the pre-test, the women were attended an educational \& training sessions.

7. The HBM based intervention was implemented in simple Arabic language in three sessions each session took 40 minutes in the following technique:

$* 1^{\text {st }}$ session related to the knowledge part which aimed to increase the awareness about osteoporosis aspect, seriousness \& susceptibility, preventive behavior \& complications, exercises, sun exposure, health beliefs items.

$* 2^{\text {nd }}$ session related to the training part: It was aimed to train women to choose healthy diet, make exercises. It included video instructions about exercise and sun exposure. Also role play in problem solving situation were used to solve calcium intake \& exercises barriers. Women were shown slides of pre \& post photos of patient bone to increase their perception of susceptibility.

$* 3^{\text {rd }}$ session was applied for revision.

* Several educational methods as group discussion, demonstration as well as, visual aids were used as posters. At the end of the sessions handouts and booklets were distributed.

* The previous sessions were repeated until the predetermined sample size was completed.

8. Then, each participant was contacted by telephone for evaluation process session and posttest that done after two months post-intervention by using the same questionnaire. 


\section{Statistical Analysis:}

Data were coded, analyzed by using SPSS version 20.0. Data were presented using descriptive statistics in the form of frequencies \& percentages and $(\chi 2)$ test was used for comparison of qualitative variables. Quantitative variables were presented as means \pm standard deviations and student $t$ test \& paired $t$ test were used for comparison. Correlation coefficient (r) was used to find correlation between two quantitative variables. Statistical significance was considered at $\mathrm{p}$-value $<0.05$.

Table (1): Frequency Distribution of the Studied Sample According to Their General Characteristics.

\begin{tabular}{|c|c|c|c|}
\hline \multirow[t]{2}{*}{ Characters } & \multirow[t]{2}{*}{ Items } & \multicolumn{2}{|c|}{ No $=60$} \\
\hline & & No & $\%$ \\
\hline \multirow[t]{4}{*}{ Age (years) } & $20-$ & 4 & 6.7 \\
\hline & $25-$ & 43 & 71.7 \\
\hline & $30-35$ & 13 & 21.7 \\
\hline & Mean \pm SD & \multicolumn{2}{|c|}{$27.65 \pm 2.74$} \\
\hline \multirow{2}{*}{ Residence } & Rural & 20 & 33.3 \\
\hline & Urban & 40 & 66.7 \\
\hline \multirow[t]{2}{*}{ Occupation } & Employed & 36 & 60.0 \\
\hline & House wife & 24 & 40.0 \\
\hline \multirow{3}{*}{ Education } & Basic and below & 16 & 26.7 \\
\hline & Secondary & 30 & 50.0 \\
\hline & University & 14 & 23.3 \\
\hline \multirow[t]{4}{*}{ Marital Status } & Single & 11 & 18.3 \\
\hline & Married & 34 & 56.7 \\
\hline & Divorced & 11 & 18.3 \\
\hline & Widow & 4 & 6.7 \\
\hline \multirow[t]{2}{*}{ Breast feeding } & Yes & 33 & 55.0 \\
\hline & No & 27 & 45.0 \\
\hline \multirow[t]{2}{*}{ Smoking } & Yes & 7 & 11.7 \\
\hline & No & 53 & 88.3 \\
\hline
\end{tabular}

Table (1) shows the general characteristics of studied sample. It was found that the age ranges from 20 -35 years with average $27.65 \pm 2.74$ years. Out of 60 female $43(71.7 \%)$ aged $25-<30$ years, two thirds were from urban areas, $60.0 \%$ were employed, $50.0 \%$ were secondary educated, $56.7 \%$ were married, $55.0 \%$ breast feeding and $11.7 \%$ were smokers.

Table (2) Average Score of the Studied Sample's Knowledge about Osteoporosis Pre- \& postIntervention.

\begin{tabular}{|l|c|c|l|}
\hline Knowledge score & $\begin{array}{c}\text { Pre- } \\
\text { Intervention }\end{array}$ & $\begin{array}{c}\text { Post- } \\
\text { Intervention }\end{array}$ & \multirow{2}{*}{ Paired t test } \\
\cline { 2 - 3 } & Mean \pm SD & Mean \pm SD & \\
\hline Knowledge score about osteoporosis & $2.88 \pm 1.69$ & $5.27 \pm 1.55$ & $\mathrm{t}=13.270, \mathrm{P} 0.000$ \\
\hline Knowledge score about exercise & $3.03 \pm 1.74$ & $4.70 \pm 1.31$ & $\mathrm{t}=10.735, \mathrm{P} 0.000$ \\
\hline Knowledge score about Ca intake & $3.55 \pm 1.14$ & $5.25 \pm 1.09$ & $\mathrm{t}=14.509, \mathrm{P} 0.000$ \\
\hline Total knowledge score & $9.47 \pm 3.14$ & $15.22 \pm 2.56$ & $\mathrm{t}=20.046, \mathrm{P} 0.000$ \\
\hline
\end{tabular}

Table (2) represents the average score of studied sample's knowledge about osteoporosis, exercise, calcium intake and total knowledge, it was clear from this table that the total knowledge score of the study sample about osteoporosis were improved significantly from $(9.47 \pm 3.14)$ pre-intervention to $(15.22 \pm 2.56)$ postintervention with highly significant difference $(\mathrm{P}=0.000)$. 
Figure (1): Levels of Studied Sample's Knowledge about Osteoporosis Pre- \& Post-Intervention.

pre- intervention post-intervention

$71.3 \%$

$73.3 \%$

$28.3 \%$

$18.3 \%$

$8.3 \%$

$0.0 \%$

Poor knowledge $\quad$ Fair Knowledge Good knowledge

Figure (1) shows that poor knowledge level percentage significantly decreased and fair \& good knowledge percentages increased post-intervention.

Table (3): Average Score of Osteoporosis Health Belief Scale (OHBS) Pre- \&Post-Intervention.

\begin{tabular}{|l|c|c|l|}
\hline \multirow{2}{*}{ Items } & Pre- Intervention & Post- Intervention & \multirow{2}{*}{ Paired t test } \\
\cline { 2 - 3 } & Mean \pm SD & Mean \pm SD & \\
\hline Susceptibility & $15.80 \pm 3.95$ & $18.92 \pm 4.29$ & $\mathrm{t}=4.633, \mathrm{P} 0.000$ \\
\hline Seriousness & $17.00 \pm 3.76$ & $20.82 \pm 3.95$ & $\mathrm{t}=7.859, \mathrm{P} 0.000$ \\
\hline Benefits of exercise & $17.40 \pm 3.03$ & $21.73 \pm 4.32$ & $\mathrm{t}=7.294, \mathrm{P} 0.000$ \\
\hline Benefits of Ca intake & $15.95 \pm 3.11$ & $21.18 \pm 4.21$ & $\mathrm{t}=7.953, \mathrm{P} 0.000$ \\
\hline Barriers of exercise & $17.65 \pm 4.06$ & $17.03 \pm 3.70$ & $\mathrm{t}=1.428, \mathrm{P} 0.159$ \\
\hline Barriers to Ca intake & $18.62 \pm 4.27$ & $17.33 \pm 3.96$ & $\mathrm{t}=3.499, \mathrm{P} 0.001$ \\
\hline Health Motivation & $15.42 \pm 3.73$ & $21.97 \pm 6.08$ & $\mathrm{t}=8.869, \mathrm{P} 0.000$ \\
\hline
\end{tabular}

Table (3) shows the average scores of the items of osteoporosis health belief Scale (OHBS) pre- \& post-intervention. The average scores of susceptibility to osteoporosis, seriousness, benefits of exercise, benefits of calcium $(\mathrm{Ca})$ intake and health motivation were significantly increased post-intervention compared to the scores pre-intervention $(\mathrm{p}<0.05)$. While the average score of barriers of exercise and barriers to Ca intake were decreased post-intervention and was significantly only for barriers of $\mathrm{Ca}$ intake.

Table (4): Comparison of Studied Sample's Response to the Items of Osteoporosis Health Belief Scale (OHBS) Pre-\& Post-Intervention.

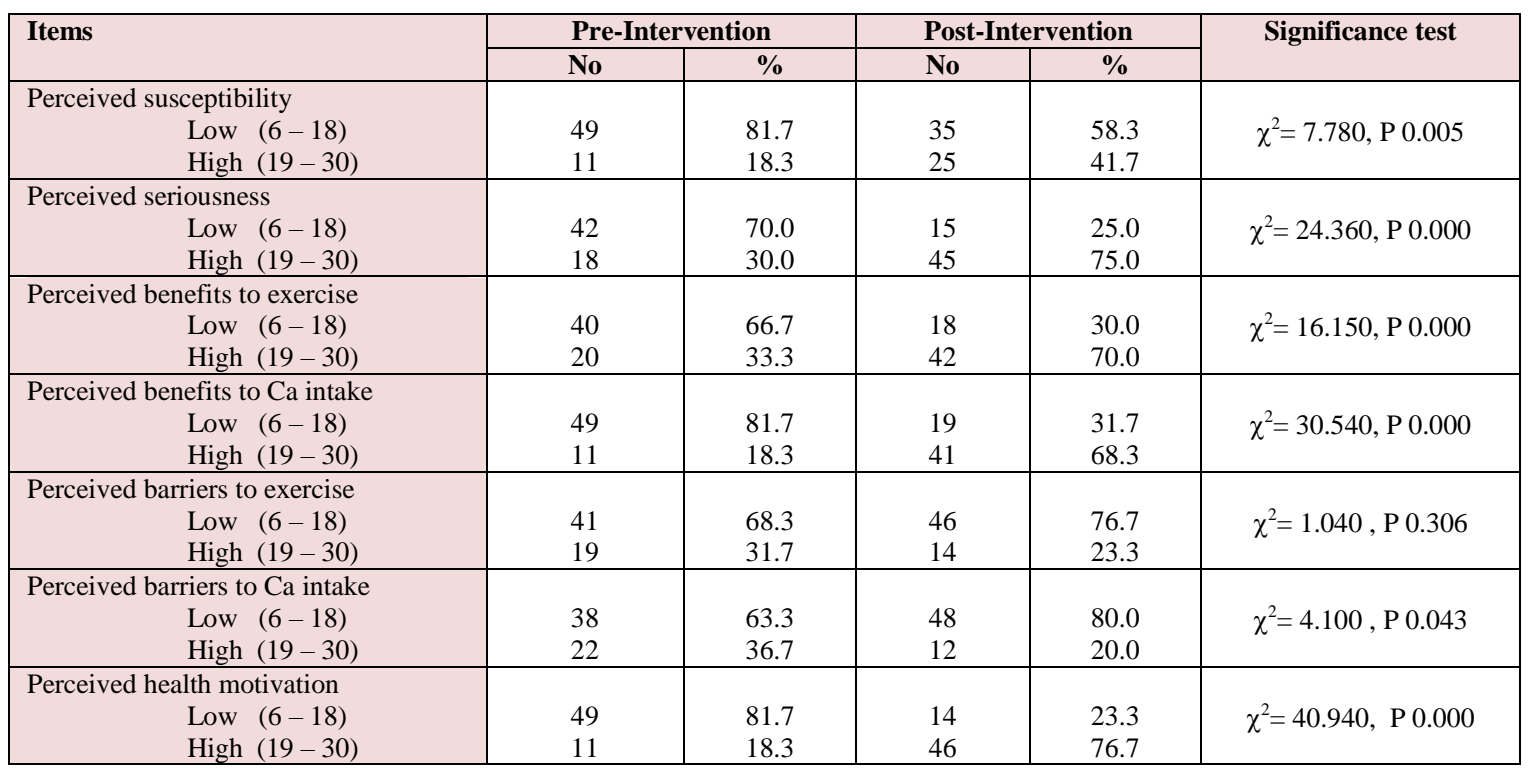


Table (4) reflects studied sample's response for osteoporosis health believes scale pre \& postintervention. It was found that their perception level about osteoporosis were improved significantly postintervention, $41.7 \%$ of them highly perceived osteoporosis susceptibility post-intervention compared with $18.3 \%$ pre- intervention , $75 \%$ highly perceived seriousness of osteoporosis post-intervention compared with $18 \%$ pre-intervention and $70 \%$ highly perceived benefit of exercises post-intervention compared with $33 \%$ preintervention, $68.3 \%$ highly perceived benefits to $\mathrm{Ca}$ intake post-intervention compared with $18.3 \%$ preintervention. Also, low level of perceived barriers of exercise and barriers to $\mathrm{Ca}$ intake were improved (increased) post-intervention and was significantly only for barriers of $\mathrm{Ca}$ intake. From this table it was also found that more than three quarter of women $(76.7 \%)$ had positive view toward their health post-intervention compared to $18.3 \%$ pre-intervention.

Table (5): Comparison of the Osteoporosis Self-Efficacy Scale (OSES) among the Studied Sample Pre-\& Post-Intervention.

\begin{tabular}{|c|c|c|c|c|c|c|c|}
\hline \multirow{2}{*}{$\begin{array}{l}\text { Statements of OSES; I am confident or } \\
\text { certain that I could: }\end{array}$} & \multirow[t]{2}{*}{ GS } & SD & D & $\mathbf{N}$ & $\mathbf{A}$ & $\mathbf{S A}$ & \multirow{2}{*}{$\begin{array}{c}\text { Significance } \\
\text { test }\end{array}$} \\
\hline & & No $(\%)$ & No $(\%)$ & No $(\%)$ & No $(\%)$ & No $(\%)$ & \\
\hline \multirow[t]{2}{*}{ 1. Begin a new or different exercise program. } & Pre & $22(36.7)$ & $29(48.3)$ & $4(6.7)$ & $4(6.7)$ & $1(1.7)$ & \multirow{2}{*}{$\begin{array}{l}\chi^{2}=63.670 \\
P 0.000\end{array}$} \\
\hline & Post & $1(1.7)$ & $7(11.7)$ & $15(25.0)$ & $34(56.7)$ & $3(5.0)$ & \\
\hline \multirow[t]{2}{*}{ 2.Change exercise habits } & Pre & $25(41.7)$ & $23(38.3)$ & $5(8.3)$ & $7(11.6)$ & $0(0.0)$ & \multirow{2}{*}{$\begin{array}{l}\chi^{2}=50.940 \\
P 0.000\end{array}$} \\
\hline & Post & $2(3.3)$ & $8(13.3)$ & $25(41.7)$ & $22(36.7)$ & $3(5.0)$ & \\
\hline \multirow[t]{2}{*}{ 3. Put forth the effort required to exercise } & Pre & $20(33.3)$ & $24(40.0)$ & $11(18.3)$ & $2(3.3)$ & $3(5.0)$ & \multirow{2}{*}{$\begin{array}{l}\chi^{2}=51.350 \\
P 0.000\end{array}$} \\
\hline & Post & $0(0.0)$ & $8(13.3)$ & $23(38.3)$ & $24(40.0)$ & $5(8.3)$ & \\
\hline \multirow[t]{2}{*}{ 4. Do exercise even if they are difficult } & Pre & $25(41.7)$ & $23(38.3)$ & $5(8.3)$ & $7(11.7)$ & $0(0.0)$ & \multirow{2}{*}{$\begin{array}{l}\chi^{2}=49.600 \\
P 0.000\end{array}$} \\
\hline & Post & $2(3.3)$ & $9(15.0)$ & $16(26.7)$ & $25(41.7)$ & $8(11.3)$ & \\
\hline \multirow{2}{*}{ 5. Exercises for appropriate length of time. } & Pre & $18(30.0)$ & $27(45.0)$ & 11(18.3) & $3(5.0)$ & $1(1.7)$ & \multirow{2}{*}{$\begin{array}{l}\chi^{2}=47.680 \\
P 0.000\end{array}$} \\
\hline & Post & $1(1.7)$ & $9(15.0)$ & $18(30.0)$ & $24(40.0)$ & $8(13.3)$ & \\
\hline \multirow{2}{*}{$\begin{array}{l}\text { 6.Do the type of exercise that I am supposed to } \\
\text { do }\end{array}$} & Pre & $23(38.3)$ & $25(41.7)$ & $7(11.7)$ & $5(8.3)$ & $0(0.0)$ & \multirow{2}{*}{$\begin{array}{l}\chi^{2}=50.380 \\
P 0.000\end{array}$} \\
\hline & Post & $2(3.3)$ & $8(13.3)$ & $22(36.7)$ & $26(43.3)$ & $2(3.3)$ & \\
\hline \multirow[t]{2}{*}{ 7.Increase calcium intake } & Pre & $18(30.0)$ & $29(48.3)$ & $8(13.3)$ & $5(8.3)$ & $0(0.0)$ & \multirow{2}{*}{$\begin{array}{l}\chi^{2}=44.840 \\
P 0.000\end{array}$} \\
\hline & Post & $1(1.7)$ & $12(20.0)$ & $15(25.0)$ & $24(40.0)$ & $8(13.3)$ & \\
\hline \multirow[t]{2}{*}{ 8.Change my diet to include more calcium food } & Pre & $15(25.0)$ & $31(51.7)$ & $10(16.7)$ & $3(509)$ & $1(1.7)$ & \multirow{2}{*}{$\begin{array}{l}\chi^{2}=47.160 \\
P 0.000\end{array}$} \\
\hline & Post & $1(1.7)$ & $10(16.7)$ & $16(26.7)$ & $27(45.0)$ & $6(10.0)$ & \\
\hline \multirow{2}{*}{$\begin{array}{l}\text { 9.Eat calcium rich foods as often as I am } \\
\text { supposed to do }\end{array}$} & Pre & $22(36.7)$ & $23(38.3)$ & $11(18.3)$ & $4(672)$ & $0(0.0)$ & \multirow{2}{*}{$\begin{array}{l}\chi^{2}=56.800 \\
P 0.000\end{array}$} \\
\hline & Post & $1(1.7)$ & $4(6.7)$ & $18(30.0)$ & $29(48.3)$ & $8(13.3)$ & \\
\hline \multirow{2}{*}{$\begin{array}{l}\text { 10. Select appropriate foods to increase my } \\
\text { calcium intake }\end{array}$} & Pre & $22(36.7)$ & $27(45.0)$ & $7(11.7)$ & $2(3.3)$ & $2(3.3)$ & \multirow{2}{*}{$\begin{array}{l}\chi^{2}=56.390 \\
P 0.000\end{array}$} \\
\hline & Post & $1(1.7)$ & $9(15.0)$ & $15(25.0)$ & $28(46.7)$ & $7(11.7)$ & \\
\hline \multirow{2}{*}{$\begin{array}{l}\text { 11.Stick to diet which gives an adequate amount } \\
\text { of calcium }\end{array}$} & Pre & $19(31.7)$ & $27(45.0)$ & $8(13.3)$ & $6(10.0)$ & $0(0.0)$ & \multirow{2}{*}{$\begin{array}{l}\chi^{2}=52.320 \\
P 0.000\end{array}$} \\
\hline & Post & $1(1.7)$ & $7(11.7)$ & $17(28.3)$ & $29(48.3)$ & $6(10.0)$ & \\
\hline \multirow{2}{*}{$\begin{array}{l}\text { 12.Obtain foods that gives an adequate amount } \\
\text { of calcium }\end{array}$} & Pre & $21(35.0)$ & $20(33.3)$ & $16(26.7)$ & $3(5.0)$ & $0(0.0)$ & \multirow{2}{*}{$\begin{array}{l}\chi^{2}=57.630 \\
P 0.000\end{array}$} \\
\hline & Post & $0(0.0)$ & $6(10.0)$ & $17(28.3)$ & $31(51.7)$ & $6(10.0)$ & \\
\hline
\end{tabular}

Table (5) shows the comparison of the osteoporosis self-efficacy scale (OSES) among study sample pre- \& post-intervention. It was found that there was a significant improvement in the percentages all the items of OSES scale post-intervention $(\mathrm{P}=0.000)$.

Table (6): Average Score of the Osteoporosis Self-Efficacy Scale (OSES) among Studied Sample Pre- \& Post-Intervention.

\begin{tabular}{|l|c|c|c|}
\hline \multirow{2}{*}{ OSES score } & Pre-Intervention & Post-Intervention & \multirow{2}{*}{ Paired t test } \\
\cline { 2 - 3 } & Mean \pm SD & Mean \pm SD & \\
\hline OSES score of items related to exercise practice & $11.68 \pm 4.64$ & $20.47 \pm 4.14$ & $\mathrm{t}=12.935, \mathrm{P} 0.000$ \\
\hline OSES score of items related to calcium intake & $11.97 \pm 4.15$ & $21.20 \pm 4.61$ & $\mathrm{t}=13.571, \mathrm{P} 0.000$ \\
\hline Total OSES score & $23.55 \pm 8.50$ & $41.62 \pm 7.97$ & $\mathrm{t}=14.548, \mathrm{P} 0.000$ \\
\hline
\end{tabular}

Table (6) shows that there are a significant increase in the mean score of the osteoporosis self-efficacy items related to exercise practice, items related to calcium intake and total OSES score post-intervention compared to them pre it. 
Figure (2): Correlation between the OSES score pre- \& post-Intervention.

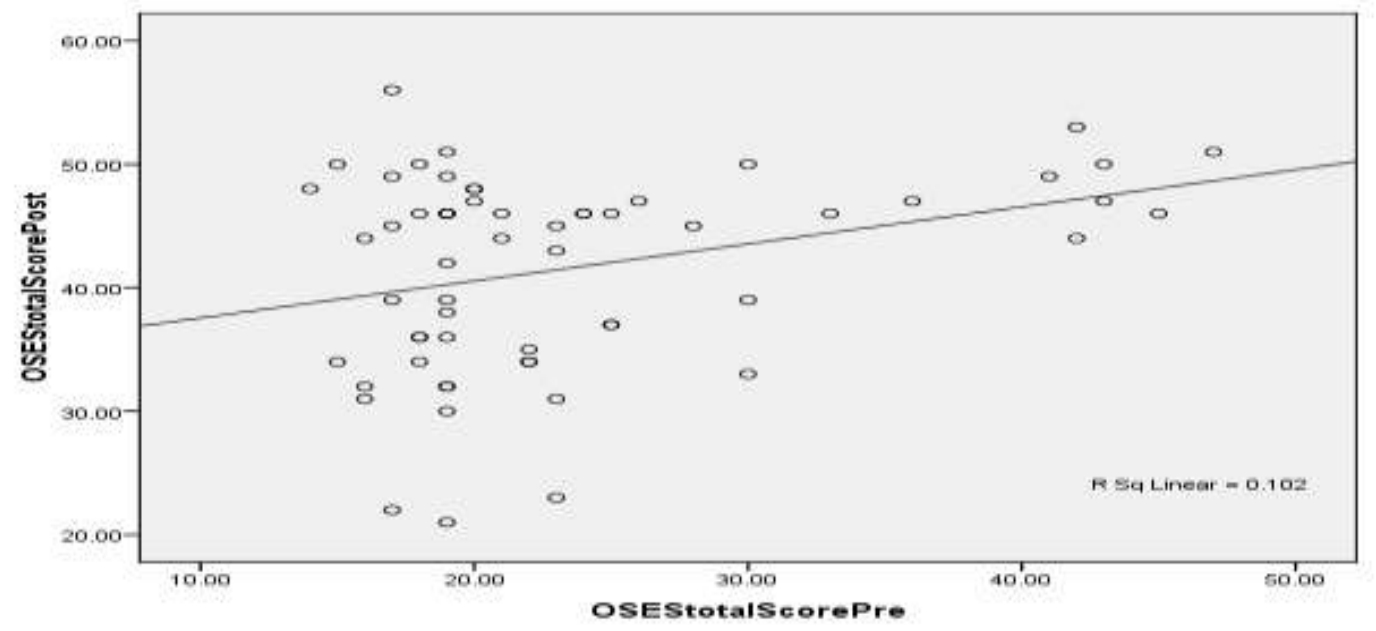

There is positive mild significant correlation between the score of OSES pre- \& postintervention $(\mathrm{r}=+0.319, \mathrm{p} 0.013)$.

\section{Discussion}

This study aimed to evaluate the utilization of health belief model to enhance the preventive health behavior about osteoporosis among young-adult females. The main study findings showed that health belief model had significantly increased the knowledge, enhancing the health beliefs, and self-efficacy for prevention of osteoporosis among the young-adult females so the research hypothesis was accepted.

The current study findings revealed that the average score of females' knowledge about osteoporosis, exercise, calcium intake and total knowledge were significantly improved postintervention. Moreover, poor knowledge level percentage significantly decreased and fair \& good knowledge percentages increased post-intervention. These results prove that the females were had deficient education regarding osteoporosis because of the fact that osteoporosis is perceived as an older age disease and consequently younger females believe that it is not essential to educate themselves about it until they are older, this was reflected in their knowledge regarding the correlation between the manner of diet and exercise and the incidence of osteoporosis. Also, it could be attributed with their interest to obtain knowledge regarding disease which associated with healthy life. Additionally, it is an indicator that intervention was effective method to increase the female's knowledge level.

These study findings were in agreement with Shahbo et al, (2016) who evaluate knowledge and self-efficacy of females about Osteoporosis in Egypt and reported that there was significant increase in the female's knowledge level post-intervention compared to pre-intervention. Furthermore, El-Sayed et al., (2013); and Sanaeinasab et al., (2013) reported by other similar osteoporosis studies that knowledge improved and increased after the educational program. Also the current study findings were supported by Abushaikha et al., (2009) who study osteoporosis knowledge among female school students in Jordan and stated that health education programs have been shown to be effective in improving knowledge and awareness among the public.

Regarding osteoporosis health beliefs, the current study results revealed that the average scores of susceptibility to osteoporosis, seriousness, benefits of exercise, benefits of calcium intake and health motivation were significantly increased after intervention compared to the scores before intervention. These results could be reflecting that the most of females were believed that osteoporosis would significantly affect their lives and the high score seems to imply that young adults understand the benefits of calcium intake.

These study results were in accordance with Ghaffari et al., (2012) study conducted in Iran to evaluate the effect of HBM on osteoporosis prevention among females stated that pre-intervention perceived susceptibility scores of females was moderate, meanwhile there was an increase in the perceived susceptibility which found significantly increase in perceived benefits physical exercise and the calcium intake. Additionally, study results were supported by Jeihooni et al., (2015) who conducted study to evaluate the effects of based on health belief model preventive program about osteoporosis among females and reported that intervention could significantly affect the female's 
beliefs about osteoporosis in all domains of the HBM. Consequently, the perceived susceptibility, seriousness, benefit of preventive health behavior and self-efficacy for prevention of osteoporosis were significantly increased, while the perceived barriers were significantly decreased.

Furthermore, the current study findings were in the same line with Zohrehkhoshnood et al., (2015) who found the education based on health belief had positive effect for increasing the average score of the perceived benefits of calcium intake and osteoporosis preventive behaviors in their study carried out in Iran about effect of education program based on health belief model for the use osteoporosis preventive behaviors among females.

Correspondingly, low level of perceived barriers of exercise and barriers to calcium intake was improved post-intervention and was significantly only for barriers of calcium intake. This result could be associated with the improvement in their knowledge score whereas these barriers are based on misbelieves that deducted by educational intervention that enable them to overcome it and increase their calcium intake regardless the perceived barriers.

Despite Sanaeinasab et al., (2013) who conducted similar study to evaluate effectiveness of education by using the HBM in preventing osteoporosis found that the majority of the females were low perceived calcium intake barriers, however there was non-significant decrease in the barriers due to unhealthy nutritional habits.

This result was concordant with similar study carried by Malak \& Toama, (2015) in Jordanian who reported that there was a significant increase the health beliefs of perceived susceptibility, perceived severity to osteoporosis, perceived benefits of exercise and perceived calcium intake to prevent osteoporosis, and to significantly reduce the perceived barriers to exercise and calcium, in order to portend an increase in self-reported health motivation.

Furthermore, the present study results showed that there was a significant improvement in the percentages of osteoporosis self-efficacy scale with significant increase in the average score postintervention. This is may be due to their understanding of self-efficacy measures which is a good predictor of engaging in osteoporosis preventive behavior.

Gammage et al., (2012) supported this result in their study about osteoporosis health belief and knowledge, who reported that there was a significant relation between the self-efficacy measures and the preventive behavior regarding osteoporosis. Similarly Hsieh et al., (2008) who examined the relationship between health beliefs in women and their osteoporosis prevention behaviors and found a significant relation between the physical exercise, nutritional performance and the self-efficacy. Over and above Sanaeinasab et al., (2013) supported these results when found a significant difference in the mean score of the females self-efficacy of physical activity and calcium intake core in favor of post intervention.

\section{Conclusion}

It was evident that the health belief model had significantly increased the knowledge, enhancing the health belief, and self-efficacy for prevention of osteoporosis among the young-adult females.

\section{Recommendations}

- Applying health belief model on wide range of female's age group on different diseases.

- Comprehensive interventions on the benefits and barriers calcium intake and the use of other behavioral modification theories.

- Further research to study the correlation between demographic characteristics and behavioral, social barriers in calcium intake in different cultural contexts.

\section{Acknowledgment}

The researchers are grateful to all females who participated in the study and all health team members for their cooperation during the study period.

\section{References}

[1]. Abushaikha L., Omran S. \& Barrouq L. (2009): Osteoporosis knowledge among female school students in Jordan, Mediterranean health journal, 15(4):906-11.

[2]. Asakawa K, Koyama K , and Yamagata Z., (2011): Effect of educational intervention using the Internet on quantitative ultrasound parameters in prevention of osteoporosis: A randomized controlled trial in young Japanese Women Int J Women's Health; 3: 415-422.

[3]. Ailinger, R., Braun, M., Lasus, H. \& Whitt, K. (2005): Factors influencing osteoporosis knowledge: a community study. Journal of Community Health Nursing, 22(3), 135-142.

[4]. Babatunde OO., Forsyth JJ., \& Gidlow C J., (2012): A meta-analysis of brief high-impact exercises for enhancing bone health in premenopausal women. Osteoporosis International; 23: 109-119.

[5]. Chan, M., Ko, C. \& Day, M. (2005): The effectiveness of an osteoporosis prevention education programme for women in Hong Kong: a randomized controlled trial. Blackwell Publishing Ltd, Journal of Clinical Nursing; 14, $1112-1123$ 
[6]. Chen, B.S., Wang, Y.C., Wu, W.S. and Li, W.H (2005): Using the health belief model to understand caregiver factors influencing childhood influenza vaccinations. Journal of Community Health Nursing; 21:2698-705.

[7]. Darba J, Kaskens L, Perez-Alvarez N, Palacios S, Neyro JL, Rejas J., (2015): Disability-adjusted-life-years losses in postmenopausal women with osteoporosis: A burden of illness study. BMC Public Health; 15:324.

[8]. $\quad$ El-Sayed M., \& Abdel Megeid FY., (2013): Osteoporosis-related life habits, knowledge and attitude among group of female employees in King Saud University. World Applied Sciences Journal; 22 (7): 919-925.

[9]. Franzén M., (2011): Osteoporosis prevention education for young women, Bachelor's thesis, Degree Programme in Nursing., 25 pages, appendices 2.

[10]. Gamal, A, and Rashed A., (2015): Effect of systematic health education on perimenopausal rural women's knowledge and practices regarding osteoporosis: Journal of Nursing and Health Science; 4(3): 31-41.

[11]. Gammage KL, Gasparotto J, Mack D., \& Klentrou P (2012): Gender differences in osteoporosis health beliefs and knowledge and their relation to vigorous physical activity in University students. Journal of American College Health; 60:58-64.

[12]. Ghaffari M., Tavassoli E., Esmailzadeh A. \& Hassanzadeh A., (2012): Effect of health belief model based intervention on promoting preventive behaviors about osteoporosis among students of female middle schools in Isfahan, Iran. Journal of Education and Health Promotion; 1-14.

[13]. Gurney S., \& Simmonds J., (2007): Osteoporosis: a teenage perspective. Physiotherapy .93, $267-272$.

[14]. Hernlund E, Svedbom A, Iverga ${ }^{\circ}$ rd M, et al (2013): Osteoporosis in the European Union: medical management, epidemiology and economic burden. A report prepared in collaboration with the International Osteoporosis Foundation (IOF) and the European Federation of Pharmaceutical Industry Associations (EFPIA). Arch Osteoporosis; 8:136.

[15]. Horan ML, Kim KK, Gendler P, Froman RD, Patel MD., (1998): Development and evaluation of the Osteoporosis Self-Efficacy Scale. Res Nurs Health; 21(5):395-403.

[16]. Hsieh CH, Wang CY, McCubbin M , Zhang S, Inouye J., (2008): Factors influencing osteoporosis preventive behaviours: testing a path model. Journal of Advanced Nursing; 62:336-345.

[17]. Jeihooni A, Hidarnia A, Kaveh M, Hajizadeh E, and Askari A., (2015): Effects of an osteoporosis prevention program based on health belief model among females. Nurs Midwifery Stud; 4(3): e26731.

[18]. Kanis JA, McCloskey EV, Johansson H, Cooper C, Rizzoli R, Reginster JY., (2013): European guidance for the diagnosis and management of osteoporosis in postmenopausal women. Osteoporosis Int; 24(1):23-57.

[19]. Kim KK, Horan ML, Gendler P., (1991a): Osteoporosis Knowledge Test, Osteoporosis Health Belief Scale, and Osteoporosis Self-efficacy Scale. Allendale: MI: Grand Valley State University.

[20]. Kim KK, Horan ML, Gendler P, Patel MK. (1991b): Development and evaluation of the Osteoporosis Health Belief Scale. Research in Nursing and Health; 14:155-163.

[21]. Malak M., \& Toama Z., (2015): The effect of osteoporosis health education program based on health belief model on knowledge and health beliefs towards osteoporosis among Jordanian female teachers. European Scientific Journal; 1: 398 .

[22]. Moodi M, \& Mood M, (2011): Evaluation of breast self-examination program using health belief model in female students. Journal of Research in Medical Sciences; 16:316-322.

[23]. National osteoporosis foundation (2011): Available at. http://www.nof.org/node/150 (accessed 11 December 2016).

[24]. National Osteoporosis Foundation (2010): Clinician's guide to prevention and treatment of osteoporosis. Washington, DC: National Osteoporosis Foundation.

[25]. Puttapitakpong P, Chaikittisilpa S, Panyakhamlerd K, Nimnuan C, Jaisamrarn U, \& Taechakraichana N., (2014): Inter-correlation of knowledge, attitude, and osteoporosis preventive behaviors in women around the age of peak bone mass. BMC Women's Health; 14: 35.

[26]. Royal College of Nursing, (2012): Going Upstream: Nursing's Contribution to Public Health: Prevent Promote and Protect, 1-24.

[27]. Sanaeinasab H, Tawakoni R., Karimizarchi A., Haji Amini Z, Farokhian A, \& Rahmati Najarkolaei F., (2013): The effectiveness of education using the health belief model in preventing osteoporosis among female students. Eastern Mediterranean Health Journal; 19: 38-44.

[28]. Sasson H. \& Carpenter CL., (2013): Achievement of peak bone mass in women is critically dependent on adolescent calcium intake. OA Sports Medicine 01; 1(2):16.

[29]. Shahbo G, El-Rahman M, \& El-mowafy R., (2016): Evaluation of knowledge and self-Efficacy about osteoporosis perception among females in the Faculty of Nursing in Port-Said, Egypt. International Journal of Caring Sciences; 9 (1):72-79.

[30]. Sunyecz J., (2008): The use of calcium and vitamin D in the management of osteoporosis. TherClin Risk Manag; 4 (4): $827-836$.

[31]. Taha M., (2011): Prevalence of osteoporosis in Middle East systemic literature review. In: Proceedings of the 10th ECOO: 2011 April 14-16. Cairo, Egypt. Available online at URL: <http://www. Scribd.com/do [accessed November 2016].

[32]. Vehei H., Taghdisi M \&Saidi M., (2007): Application of the health belief model for osteoporosis prevention among middle school girl students, Garmsar, Iran, education for health journal, 20(1): 1-11.

[33]. Watts NB, Bilezikian JP, Camacho PM., (2010): American Association of Clinical Endocrinologists Medical Guidelines for Clinical Practice for the diagnosis and treatment of postmenopausal osteoporosis. Endocr Pract; 16 (3): $1-37$.

[34]. World Health Organization, (2012): WHO scientific group on the assessment of osteoporosis at primary health care level: summary meeting report. Available at: http://www.who.int/chp/topic Osteoporosis.pdf, accessed on 12 November 2016.

[35]. Wright NC, Looker AC, Saag KG., (2014): The recent prevalence of osteoporosis and low bone mass in the United States based on bone mineral density at the femoral neck or lumbar spine. J Bone Miner Re; 29(11):2520-6.

[36]. Zohrehkhoshnood, Anoosheh M, Mohammadi E, \& Haji Zadeh E., (2015): Comparative survey the effect of education based program on health belief model for the use osteoporosis preventive behaviors of the girl's osteoporotic and non-osteoporotic mothers. Sch. J. App. Med. Sci; 3(6A): 2200-2206. 